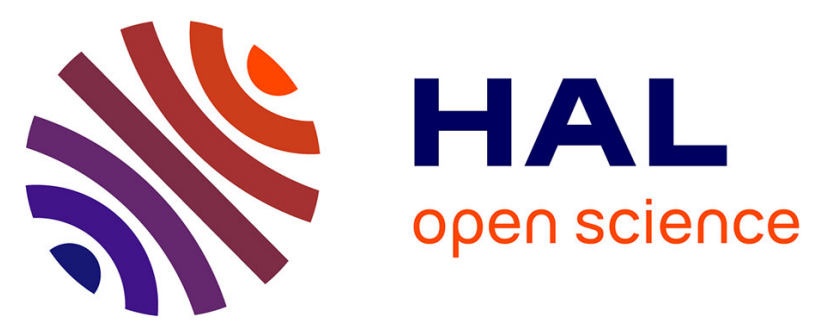

\title{
TRANSIENTS IN CW LASER HEATING OF SEMICONDUCTORS : GENERAL METHOD, ANALYTICAL SOLUTIONS AND ILLUSTRATIONS
}

A. Maruani, Y. Nissim, F. Bonnouvrier, D. Paquet

\section{- To cite this version:}

A. Maruani, Y. Nissim, F. Bonnouvrier, D. Paquet. TRANSIENTS IN CW LASER HEATING OF SEMICONDUCTORS : GENERAL METHOD, ANALYTICAL SOLUTIONS AND ILLUSTRATIONS. Journal de Physique Colloques, 1983, 44 (C5), pp.C5-87-C5-90. 10.1051/jphyscol:1983514 . jpa-00223094

\author{
HAL Id: jpa-00223094 \\ https://hal.science/jpa-00223094
}

Submitted on 1 Jan 1983

HAL is a multi-disciplinary open access archive for the deposit and dissemination of scientific research documents, whether they are published or not. The documents may come from teaching and research institutions in France or abroad, or from public or private research centers.
L'archive ouverte pluridisciplinaire HAL, est destinée au dépôt et à la diffusion de documents scientifiques de niveau recherche, publiés ou non, émanant des établissements d'enseignement et de recherche français ou étrangers, des laboratoires publics ou privés. 


\title{
TRANSIENTS IN CW LASER HEATING OF SEMICONDUCTORS : GENERAL METHOD,
} ANALYTICAL SOLUTIONS AND ILLUSTRATIONS

\author{
A. Maruani ${ }^{+}$, Y.I. Nissim, F. Bonnouvrier and D. Paquet \\ C.N.E.T., Laboratoire de Bagneux*, 196 me de Paris, 92220 Bagneux, France
}

Résumé - La méthode des transformées intēgrales est appliquēe à l'équation nontinéaire de la chaleur pour déterminer 1 'échauffement d'un semiconducteur irradié par un laser continu. Pour le transitoire, on traite exactement les nonlinéarités dues aux variations de la conductivité thermique et adiabati quement celles dues aux variations de la chaleur spécifique. On envisage 1 'influence du coefficient d'absorption, et de la forme du faisceau laser. Pour tous les cas considérés, les expressions obtenues sont analytiques.

\begin{abstract}
The method of integral transforms is applied to the nonlinear heat equation to determine the heating of a semiconductor irradiated by a $\mathrm{CW}$ laser beam. For the transient, the nonlinearities associated to the variations of the thermal conductivity are treated exactly and those due to the variations of the specific heat adiabatically. The influence of the absorption coefficient, and the shape of the laser beam are treated. For all the cases considered, the results are in analytical form.
\end{abstract}

Midway between the continuous regime and the very fast, far from equilibrium, regime, the transients in $\mathrm{CW}$ laser heating of semiconductors address two problems of noticeable importance : a fundamental one concerning phase transitions for intermediate time scales and a technological one concerning laser processing of materials. In that respect, a reliable knowledge of the actual temperature rise is in order. Measurements are difficult and exact computations cumber some. This paper deals with the problem of calculating the temperature rise with an operational accuracy, and with a formalism leading to simple expressions. The basic idea is the systematic use of integral transforms for all spatial and temporal variables. That idea was pioneered by Lax/1/ who presented general results for the stationary case, linear and nonlinear. By the latter, it is meant that account is made of the variation of thermal coefficients with the true temperature, which will be denoted hereafter by $T$. In the stationary case, only the thermal conductivity $K(T)$ need be accounted for. The standard procedure is to perform a Kirchhoff transform on the nonlinear Fourier equation: through that transform, the equation for $T$ becomes a linear Fourier equation for some variable $\theta$, then one solves for $\theta$. Finally one has to go back from. the linear temperature rise $\theta$ to $T$, and that is done through a quadrature involving $K(T)$ only.

In the transient case, both variations of $K(T)$ and the specific heat $C(T)$ (or the diffusivity $D(T)=K(T) / C(T))$ have to be included in the calculation. Strictly speaking, the Kirchhoff transform is no more valid in that case. A novelty of this paper is to present how one can overcome that difficulty and still eventually exhibit tractable analytical results. Section $I$ is devoted to a brief review of the model $/ 2$ ! and a discussion of the incidence of $C(T)$ on the transient regime. Section II presents some results for selected practical cases.

\footnotetext{
${ }^{+}$Present address :

ENST/EPH, 46 rue Barrault, 75013 Paris

"Laboratoire associé au CNRS (LA 250)
} 


\section{I - THE MODEL.}

We shall restrict the mathematical formalism to what is strictly needed for this presentation. It is assumed that the laser is specified by its intensity distribution as a function of the radial distance $r$ : $I(r)=I f(r / r)$ where $r$ is a characteristic length of the beam and $I_{0}=P_{0} / 2 \pi r$. For a gaussian beam $f(r)=$ $\exp -r^{2} / 2 r{ }^{2}=\exp -R^{2} / 2$, for an uniform beam $f(r)=1$ for $r \leqslant r \quad(R \leqslant 1)$ and nul1 outside. The sample is infinite in the $x, y$ directions and semi-infinite for $z>0$. Cylindrical coordinates are then appropriate. The laser is switched on at $t=0$, so that it is described in the time domain by the Heavyside step function $H(t)$. For the considered wavelength, the effective linear absorption coefficient is $\alpha$. The reduced quantities are utilized $W=\alpha r_{0} \quad Z=z / z_{0}$ and $n=K / C_{0}{ }^{2}$ to obtain the nonlinear fourier equation :

$$
\frac{1}{R} \frac{\partial}{\partial R}\left(R \frac{\partial T}{\partial R}\right)+\frac{\partial^{2} T}{\partial z^{2}}-\frac{1}{\eta} \frac{\partial T}{\partial t}=\frac{-W P_{0}}{2 \pi K r_{0}} f(R) \exp -W Z
$$

submitted to the initial condition (2) $T(t=0)=T$ and the Neumann condition (3) $(\partial T / \partial z)_{z=0}=0$. Equations (1), (2) and (3) completely specify the problem. Let us assume for the moment that $C(T)=C\left(T_{0}\right)=C$ ste. Then equation (1) can undergo a Kirchhoff transform and eventually be read as (1), but with $K(T)$ replaced by $K\left(T_{0}\right)$ and $T$ by $\theta$ as mentioned above. Then a Laplace transform is performed on $\theta(t)$ and $a$ Bessel transform on $\Theta(R): \theta(R, Z, t) \rightarrow \Theta(\lambda, Z, p)$. Similar transforms are done on the right hand side of this equation. One has now a linear differential equation for $\Theta(\lambda, Z, p)$ which is trivial to solve, accounting for conditions (2) and (3). Back to the original variables, it is shown that for a gaussian laser beam :

$$
T(0,0, t)=\frac{P_{0}}{2 \pi K\left(T_{0}\right) r_{0}} \int_{0}^{\frac{K\left(T_{0}\right) t}{C\left(T_{0}\right) r_{0}^{2}}} \frac{\exp \left(W_{u}^{2}\right) \operatorname{erfc}(W \sqrt{u})}{1+2 u} d u
$$

details and extensions are to be reviewed in a forthcoming publication. Now, from room temperature throughout the solid phase regime the thermal conductivity for most semiconductors is fairly well fitted by (5) $K(T)=k /\left(T-T_{k}\right)$ which shows that the major contribution to this parameter comes from the phonon mean free path dependance 13/. This particular form allows the quadrature back to $T$ to be performed leading to

$$
T(R, Z, t)=T_{k}+\left(T_{0}-T_{k}\right) \exp \left\{\Theta(R, Z, t) /\left(T_{0}-T_{k}\right)\right\}
$$

The above expression would be exact if $C(T)$ were constant; it is not. However, the diffusivity writes (7) $D(T)=d /\left(T-T_{d}\right)$ where the value of' $T_{d}$ is within a factor 2 from the value of $T_{k}$. The variations of $C(T)$ are then much smoother than those of $K(T)$ and, to first order, can be neglected. (In any case the stationary temperature is independant of $\mathrm{C})$. A further step along that line is to replace selfconsistently $C\left(T_{0}\right)$ in (6) by $C(T)$. It so happens that the result, which in the general case would present as an implicit equation for $T$ can, in the specific case (6) and (7) be inverted, leading to :

$$
t=\frac{r_{e}^{2}}{2 D(T)} \frac{K(T)}{K\left(T_{0}\right)} \operatorname{tg}^{2}\left\{\left(\frac{\pi}{2}\right)^{1 / 2} \frac{2 \pi\left(r_{0}\right.}{P_{0}} \log \frac{K\left(T_{0}\right)}{K(T)}\right\}
$$

instead of

$$
t=\frac{r_{0}^{2}}{2 D\left(T_{0}\right)} \operatorname{tg}^{2}\left\{\left(\frac{\pi}{2}\right)^{1 / 2} \frac{2 \pi k r_{0}}{P_{0}} \log \frac{K\left(T_{0}\right)}{K(\pi)}\right\}
$$


the validity of the result is submitted to the validity of the adiabatic approximation, expressing that at each moment, the time scale for the temperature change is much shorter than the time scale for the variations of $C(T)$. While numerical analysis will be presented elsewhere, we sketch here the argument : (8) is valid provided $T^{-1} \partial T / \partial t<<C^{-1} \partial C / \partial t$ or $T^{-1} C \partial T / \partial C<<1$, which is the case in most semiconductors. some implications of that procedure are now described.

\section{II - APPLICATIONS}

We recall briefly (Fig.1) one result concerning the maximum temperature rise for an infinite absorption coefficient, in the conditions described in ref/2/. The influence of $\alpha$ on the stationary case is sketched in Fig.2, which is basically the same curve described by Lax/1/ al though derived from a different formalism, leading to different analytical expressions. It results from this curve that it is useless to correct for $\alpha$ as soon as $W \geqslant 10$.

Consider now two laser beams : gaussian and uniform, but with such intensities and beam radij that the total energy deposited on the one hand, the maximum temperature rise on the other hand are respectively identical. The radial dependance of the surface temperature in the case of infinite absorption is drawn in fig.3, showing up a smoother profile in the uniform laser case.
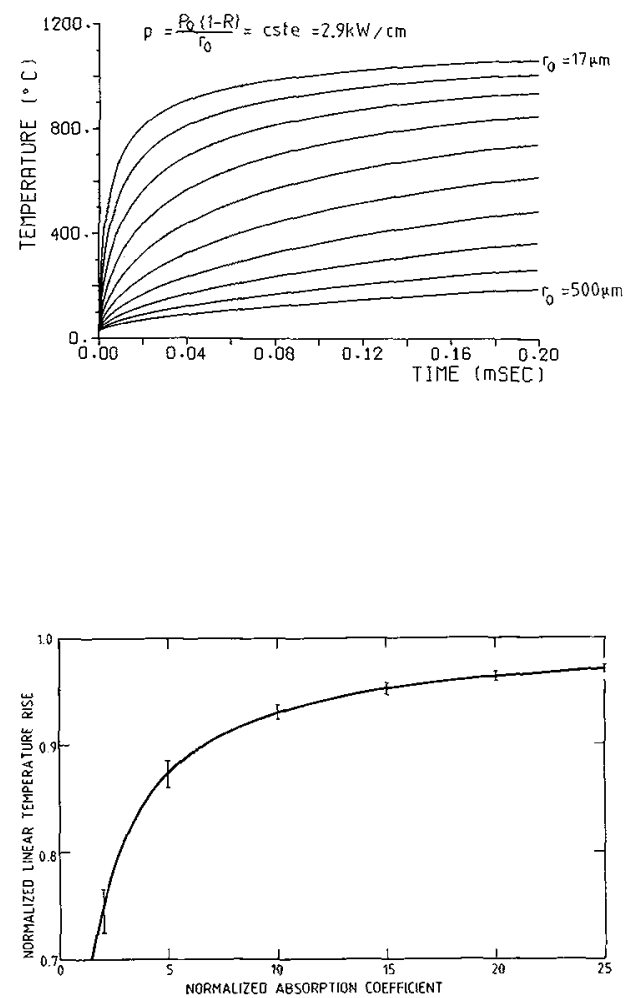

Fig.1 : Transient regime for a $\mathrm{CW} 1$ aser beam as a function of the beam waist, and in the case of infinite $\alpha$. The maximum temperature rise is calculated with data relevant to $\mathrm{Si}(/ 2 /, / 3 /)$.
Fig.2 . Naximum temperature $r$ ise as a function of $W=$ or 0 . Actually the curve represented here is the mean value between two very simple analytical expressions respectively under and overestimating the exact formula. As can be seen, the difference between those two expressions is a decreasing function of $w$. 
The influence of $W$ on the transient is shown in Fig.4 for a gaussian laser beam. No time constant can be defined since the process is by no means exponentia1. The time scale is strongly depending on the beam waist and the exciting energy, but is in the range of some microseconds. Some asymptotic values are readily deduced from fig. 2 ; note that for the standard conditions of those calculations $\left(P_{a b s} / \mathrm{r}_{0}\right)=2900 \mathrm{~W} . \mathrm{cm}-1$ leading to the linear temperature rise and the corresponding true temperature of respectively $385^{\circ} \mathrm{C}$ and $1203,4^{\circ} \mathrm{C}$, in the case of infinite $\alpha$.
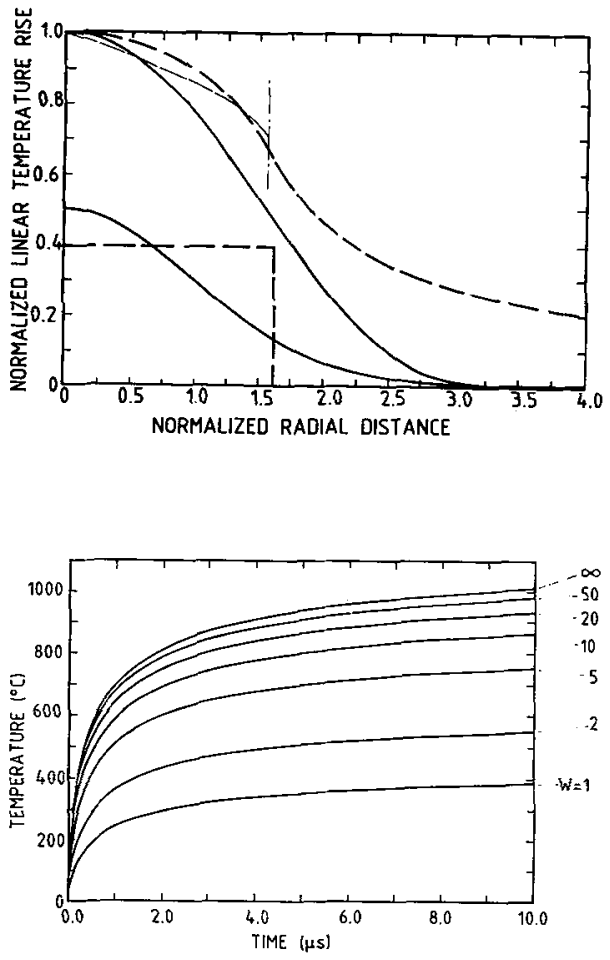

Fig.3 : Normalized temperature rise as a function of the normalized radial distance for a gaussian (solid curve) and a uniform (dashed curve) laser beam. In both cases, the energy and the maximum temperature rise are identical. The lower curves represent the energy distribution in the spots. The thin dashed curve is a very simple approximation of the thick one, valid for $R \in R_{0}$ (uniform beam). In both cases, $W=\infty$.
Fig.4 : Non linear transient regime for a gaussian laser beam, as a function of $W=\alpha r$. Each curve is respectively the mean between two under and over estimates. For all curves, $P_{a b s} / r_{0}=2900 \mathrm{~W} . \mathrm{cm}^{-1}$. Thermal data are those of Si. Asymptotic values are to be deduced from fig.2.

As a conclusion further applications of the method described in a previous publication have been described. These applications are still thoroughly described simply and analytically.

\section{REFERENCES}

[1] LAX M., J. Appl. Phys. 48 (1977) 3919 and al so LAX M., App]. Phys Lett. 33 (1978) 786

[2] MARUANI A., NISSIM Y.I., BONNOUVRIER F. and PAQUET D., to be published in "Laser Solid Interactions and Transient Thermal Processing of Materials" edited by Narayan J.,Brown W.L. and Lemons R.A.

[3] NISSIM Y.I., PhD Thesis Stanford University (1981) and also

NISSIM Y.I., LIETOILA A., GOLD R.B. and GIBBONS J.F., J. Appl. Phys 51 (1980) 279 